\title{
Priorities of innovative activity of Orenburg region's subsoil users
}

\author{
Anna Novikova, Olga Eremenko*, and Irina Vashuk \\ National University of Oil and Gas Gubkin University, branch in Orenburg, 460052, 20, Yunykh \\ Lenintsev st., Russia
}

\begin{abstract}
Instability of the global energy market and internal problems of operation of the mature Orenburg oil and gas condensate field have led to the need for innovation. The relevance of new technologies is explained by the fact that since 1967, the development of the field has been complicated by the aggressiveness of the extracted hydrogen sulfide gas and the activity of water manifestations. The lack of effective technologies has led to a deterioration in the conditions of field preparation of raw materials, a drop in reservoir pressure and flow rate of wells, and an increase in their water content. As a result, oil and gas production and environmental and economic efficiency indicators are rapidly declining. In this regard, priorities have been set for technological improvement of subsurface use: 1) reduction of operating costs through the introduction of resource-saving and energyefficient technologies; 2) application of environmental innovations in order to reduce the man-made impact on the environment. This paper presents measures aimed at solving the identified problems: re-equipment of oil wells with an automated plunger-lift on solar batteries without reconstruction of fountain fittings; arrangement of a system for utilization of gases degassing of sulfur on the Claus process plant; etc.
\end{abstract}

\section{Introduction}

Among the global problems of the Russian oil and gas industry, the main ones are: imperfect industry legislation, difficult access to new technologies and sources of their financing as a result of the introduction of sanctions; stricter environmental and safety requirements, etc [4]. However, the high potential of oil and gas development in the Orenburg region is determined by several factors, most important among which are access to raw materials, availability of markets, availability of skilled labor, developed transport and production infrastructure (fig.1).

\footnotetext{
${ }^{*}$ Corresponding author:economngp@mail.ru
} 


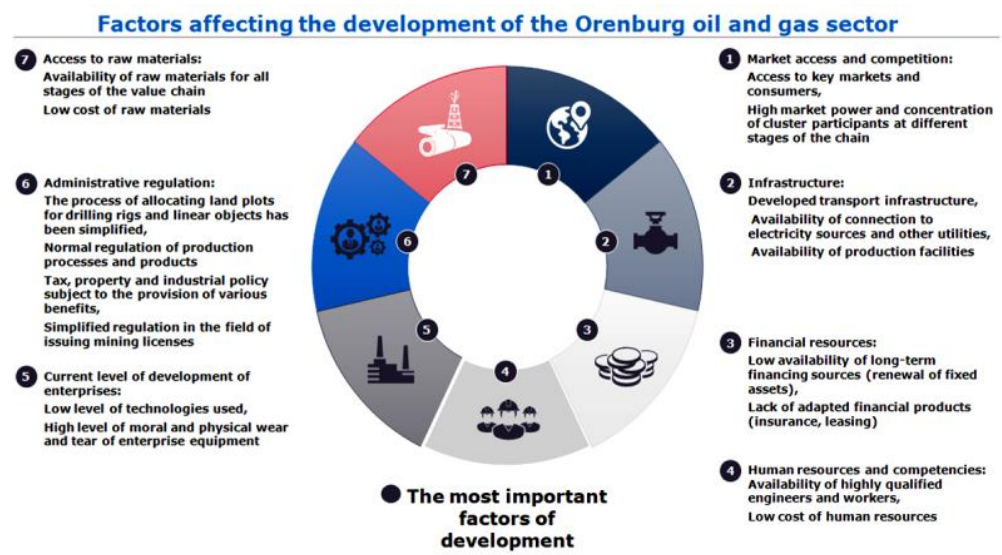

Fig. 1. Factors influencing and determining the development prospects of the Orenburg oil and gas complex.

The factors "Administrative regulation», «Financial resources» and «Current level of development of enterprises» are factors that have a low level and have a negative impact on subsurface use in the Orenburg region. In addition, the current low level of operational efficiency of the oil and gas field is primarily due to the high level of obsolescence of production assets and the problems of their long-term operation [9].

The Orenburg oil and gas condensate field is unique in the composition of the extracted raw materials and the complexity of the geological structure. This made it possible to combine mining and processing facilities that produce 22 types of products [6]. From the very beginning, the development of the field was complicated by the aggressiveness and toxicity of the extracted raw materials (containing hydrogen sulfide, mercaptans and helium), as well as the heterogeneity of the reservoir pressure distribution, uneven gas processing.

Currently, the share of reserves in low-permeable reservoirs has increased; salt deposits; water activity; the composition of reservoir fluids and the conditions for preparing raw materials deteriorated (since 1986, the method of low-temperature separation was replaced by mechanical separation, which led to a decrease in the quality of raw materials). Problems of obtaining liquid hydrocarbons from associated oil, resins and asphaltenes have also become more acute. Production is reduced due to depletion of the field's reserves (for free gas- $72.9 \%$, stable condensate-39.6\%) and reduced well productivity (fig. 2).

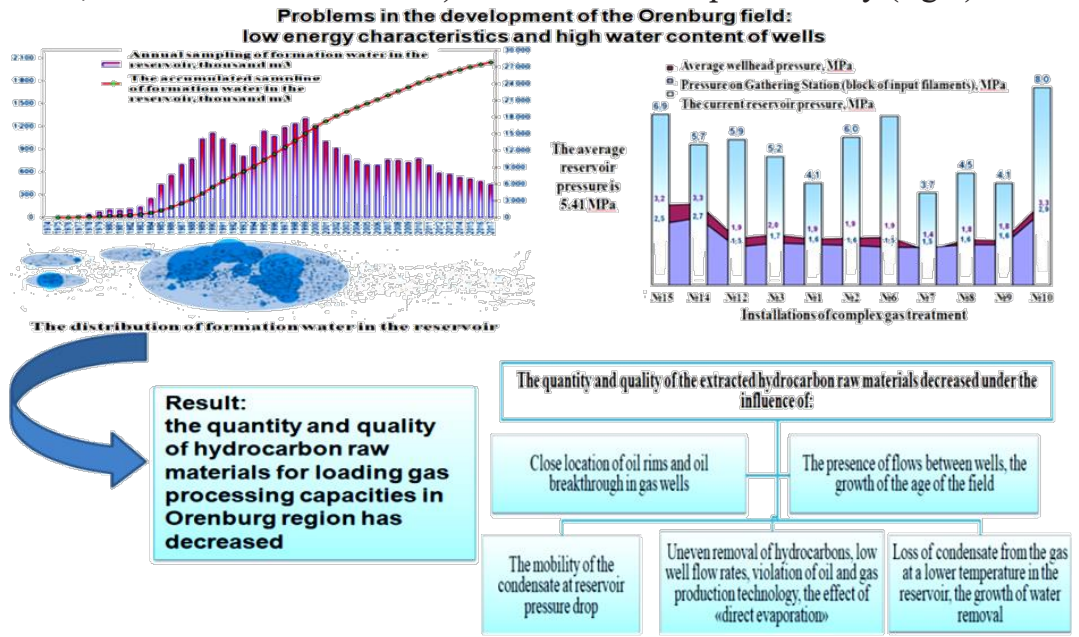

Fig. 2. The current problems of exploitation of the Orenburg field. 
The current reservoir pressure decreased by $73.5 \%$ and amounted to $5.41 \mathrm{MPa}$, the average flow rate of wells decreases annually by $2.6 \%$ and reaches the level of 58.2 thousand $\mathrm{m}^{3} /$ day [5]. In the structure of the operating well stock, $33.5 \%$ is occupied by water-cut wells, the operation of which is characterized by: low working pressure at the wellhead; minimal profitability due to the inability to provide working depression; systematic shutdowns and reallocation of the load on «dry» wells. In addition, the preparation of raw materials at complex gas treatment installations has deteriorated. Currently in the system: «complex gas treatment installations - booster compressor station gas processing plant» gas humidity exceeded $80 \%$, which leads to unstable operation of acid gas conversion plants (Claus)[8]. Under the influence of all these factors, the unit cost of the complex's products, in particular commercial gas, is growing, and the indicators of environmental-economics efficiency are deteriorating. The situation is aggravated by the fact that the main part of products falls under state regulation of pricing, implemented by the Federal energy Committee of the Russian Federation, which does not allow to compensate for losses in the profitability of target products and falling revenue) [7]. The main oil and gas producing enterprise in the region - «Gazprom dobycha Orenburg» - is located in the loss-making zone.

\section{Results and discussion}

he general trend is to increase costs and reduce profitability. Moreover, the main role in increasing the cost of production was played by the growth of: electricity tariffs when switching to the terms of a retail buyer; capital repairs costs due to a high level of depreciation of funds; rent for fixed assets owned by Gazprom. For dry gas, the largest negative result was obtained, which is explained not only by a decrease in production and an increase in energy consumption when wells are flooded, but also by a decrease in the gas sales price.

Today, in the context of a sharp drop in the price of hydrocarbons as a result of the Covid-19 pandemic, as well as the global economic crisis, the world's leading oil and gas companies are also faced with the need to reduce costs. In this regard, in a number of countries (especially in the Nordic countries, whose economy, like in Russia, is characterized by a high specific energy consumption for the production of 1 dollar of Gross Domestic Product), the main dominant of future development has chosen resource conservation and energy efficiency of industrial production.

As the technologies recognized as the most successful in the activities of leading global companies, we would like to note the following areas of resource-saving innovations (table 1):

1) at the equipment level - solutions that allow increasing energy efficiency by increasing the efficiency of equipment and reducing losses;

2) at the technological level - energy innovations based on changing the principles of technological installations in subsurface use;

3 ) at the organizational level, new organizational-economic tools are being introduced to achieve resource-saving goals.

Table 1. The most successful resource-saving innovations in foreign companies

\begin{tabular}{|l|l|l|l|}
\hline $\begin{array}{c}\text { Areas of } \\
\text { innovation }\end{array}$ & \multicolumn{1}{|c|}{ USA Saudi Arabia } & \multicolumn{1}{|c|}{ Iran } \\
\hline Technical & $\begin{array}{l}\text { Implementation of } \\
\text { transformation } \\
\text { systems, power factor } \\
\text { regulation, energy } \\
\text { converters and its }\end{array}$ & $\begin{array}{l}\text { Use of solar panels, } \\
\text { cooling paints for } \\
\text { equipment, } \\
\text { intelligent voltage } \\
\text { controllers, etc. }\end{array}$ & $\begin{array}{l}\text { The nanoantenna in the } \\
\text { solar glass, } \\
\text { thermoelectric generator } \\
\text { of the vortex type, } \\
\text { geoactive buildings, }\end{array}$ \\
\hline
\end{tabular}




\begin{tabular}{|l|l|l|l|}
\hline & accounting. & \multicolumn{2}{|c|}{$\begin{array}{l}\text { solar collectors, led } \\
\text { technology, etc. }\end{array}$} \\
\hline Technological & $\begin{array}{l}\text { Switching to renewable energy sources to increase environmental- } \\
\text { economic efficiency }\end{array}$ \\
\hline $\begin{array}{l}\text { Organizational- } \\
\text { economic }\end{array}$ & $\begin{array}{l}\text { Use of tax incentives } \\
\text { when investing in } \\
\text { resource conservation, } \\
\text { creation of economic } \\
\text { mechanisms for energy } \\
\text { saving; formation of } \\
\text { new pricing policy for } \\
\text { energy resources, etc. }\end{array}$ & $\begin{array}{l}\text { Using the mechanism } \\
\text { of public-private } \\
\text { partnership, creating } \\
\text { economic } \\
\text { mechanisms for } \\
\text { energy saving, etc. }\end{array}$ & $\begin{array}{l}\text { Training and retraining } \\
\text { of specialists; } \\
\text { motivation of personnel } \\
\text { to save resources; } \\
\text { increasing the level of } \\
\text { technical equipment of } \\
\text { production, } \\
\text { intellectualization of } \\
\text { energy audits, etc. }\end{array}$ \\
\hline
\end{tabular}

By combining the innovations listed in table 1, subsurface users increase the integral indicators of their activities, such as: capitalization, profit, profitability.

All this information allowed us to formulate priority innovations aimed at: improving the efficiency of the Orenburg subsurface users; increasing the full life cycle of the Orenburg oil and gas condensate field and improving the efficiency of its further development in the conditions of falling production by introducing resource-saving innovations, reducing product losses. Let's look at the technologies that allow us to implement these goals in practice:

1) Application of an automated control system for gas-lift gas of a productive well formation. Currently, $71.4 \%$ of wells are operated using the gas-lift method, which has its drawbacks due to the lack of automation of gas supply management. The plunger-lift is used in oil wells with a high gas factor and low downhole pressure, low productivity [6]. Despite the comparative simplicity of the design, plunger-lift units were not widely used before, which was due to the need for significant reconstruction of the ground equipment of the well and the low efficiency of removing liquid from deep wells. However, modern sets of equipment successfully solve these problems.

There are several ways to automate this process. We focused on the Russian automatic gas-lift control and regulation system, which will allow us to effectively measure the volume and regulate the flow of gas-lift gas in the conditions of the Orenburg field; reduce equipment downtime associated with hydrate formation; maintain proper accounting and operational control of the well operation mode (fig. 3).

Oil wells of the Orenburg field are suitable for the above characteristics of using plunger-lift. The option of equipping an oil well with a plunger-lift without reconstruction of the fountain fittings and powered by solar energy is offered. This option has a number of advantages:

1. Low capital costs compared to balancing pumping units;

2. Reduced maintenance and repair of equipment;

3. Decrease capital repair costs, since periodic repairs are not required;

4. The possibility of continuous operation of the well is provided, which leads to an increase in oil production;

4. Reducing paraffin and salt deposits, which eliminates the need for chemical treatment or swabbing of the well;

5. Reduction of the number of technological equipment and corresponding reduction of energy consumption. 


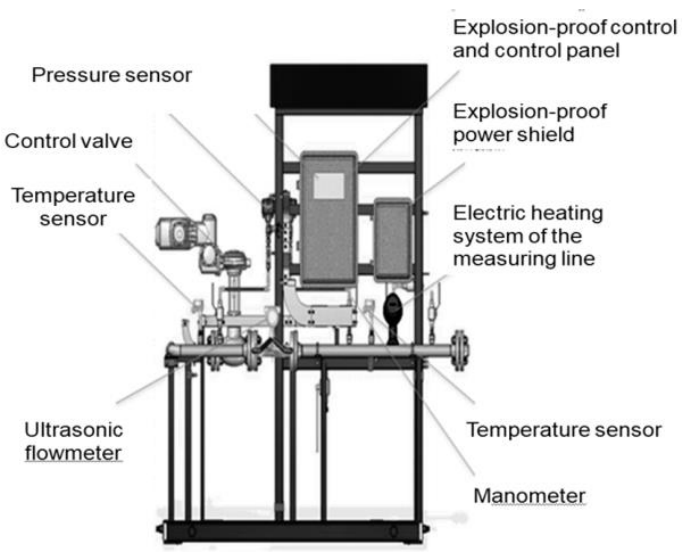

Fig. 3.Scheme of automation of plunger-lift

Implementation of this innovation will allow improve the efficiency of the mining process, including: increase oil production; reduce the consumption of gas lift gas or own (reservoir) gas (in some cases, enough reservoir energy to lift oil), decrease electricity consumption (table 2).

Table 2. Efficiency of implementation of a solar-powered plunger-lift on the Orenburg field

\begin{tabular}{|l|c|}
\hline \multicolumn{1}{|c|}{ Name of the indicator } & Value \\
\hline $\begin{array}{l}\text { The cost of equipment including installation and } \\
\text { commissioning per well, thousand rubles }\end{array}$ & 2431.661 \\
\hline Expected increase in oil production, thousand tons/year & 19.557 \\
\hline Energy saving, $\mathrm{kWh} /$ year & 272652 \\
\hline $\mathrm{NPV}$, million rubles. & 26.5 \\
\hline Internal rate of return, $\%$ & 43.3 \\
\hline Payback period, years & 2,9 \\
\hline
\end{tabular}

2) Reducing the impact of the Orenburg gas chemical complex on the environment can be solved by introducing innovations in the system of utilization of degassing gases of sulfur at the Claus plant for conversion to sulfur. The scheme for collecting degassing gases is shown in figure 4. 


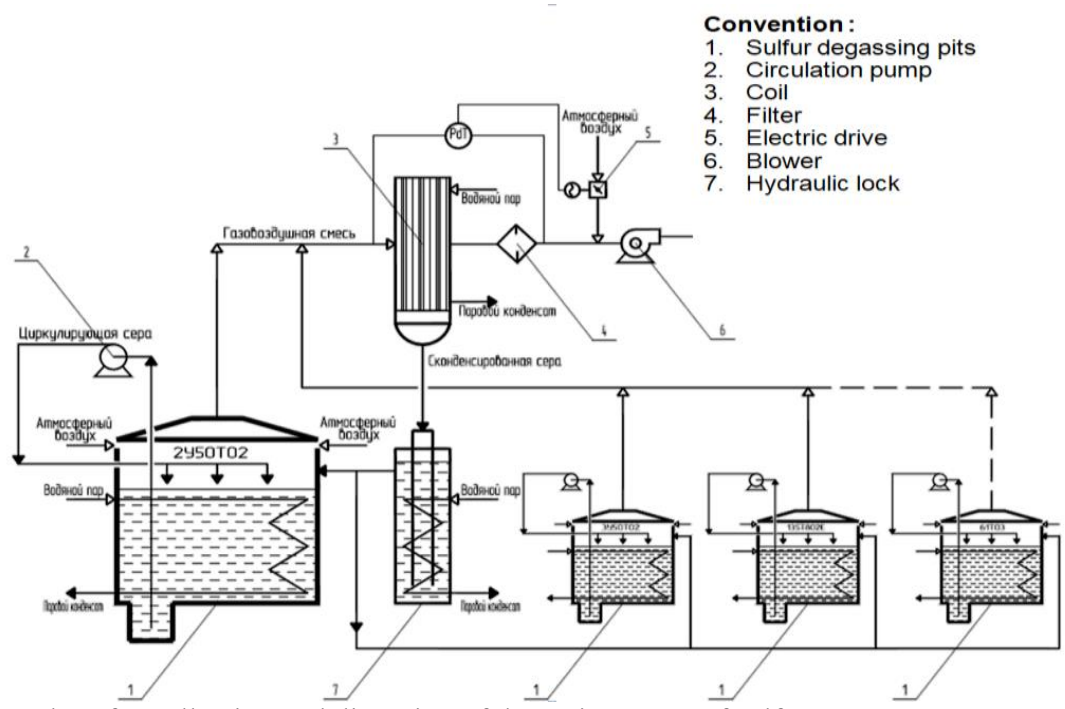

Fig. 4. Flow chart for collecting and disposing of degassing gases of sulfur

Now gases are directly released into the air without afterburning with a maximum content of hydrogen sulfide, which has a hazard class 2 . It is proposed, as shown in the figure, to collect the gases formed during the degassing of liquid sulfur from the degassing pits of the desulphurization plants and send them through the common flue to the air inlet for supply to the thermal stage of the installation. There is a heat exchanger installed, passing through which sulfur begins to be released from the gases. Its particles stick to the heat exchanger tubes, gradually making it difficult to pass the gas flow. When the passability becomes critical, the differential pressure sensor is triggered. Immediately along the inner space of the tubes, steam at a temperature of 120 degrees begins to be supplied from the low-pressure steam collector. The sulfur condenses and is drained into the degassing pits through the hydraulic seal, and the air with the remaining hydrogen sulfide enters the afterburning furnace, where it is used as raw material. This technology will reduce hydrogen sulfide emissions to the atmosphere by 364 tons per year and produce 341 tons of granulated sulfur $\mathrm{h}$, reduce the consumption of fuel gas for afterburning furnaces(table 3).

Table 3.Efficiency indicators for the system of degassing gases of sulfur at the Claus plant of the Orenburg gas processing plant

\begin{tabular}{|l|c|}
\hline \multicolumn{1}{|c|}{ Name of the indicator } & Value \\
\hline 1.Reduction of hydrogen sulfide emissions into the air, tons/year & 364 \\
\hline 2.Additional sulfur production, tons/year & 341 \\
\hline 3.Additional revenue from sales of sulfur, thousand rubles/year & 637.678 \\
\hline $\begin{array}{l}\text { 4.Reduction of operating costs for the installation by reducing energy } \\
\text { costs, thousand rubles/year }\end{array}$ & 112.693 \\
\hline 5.Reduction of the fee for air emissions, thousand rubles/year & 15.481 \\
\hline 6. Additional profit, thousand rubles/year & 765.852 \\
\hline
\end{tabular}

3) Increasing the capacity utilization of the Orenburg gas processing plant and extending the life cycle of the field is possible due to the beginning of the development of high-molecular raw materials (HMWRM). In general, HMWRM are heavy hydrocarbons produced by the carbonate oil and gas-producing system of fields and are part of the fractions of oil and condensate that are in a stationary state associated with the reservoir. According to its composition, it is distinguished: oils, asphaltenes, resins, as well as rare 
and noble metals in high concentrations. The estimated resources of high-molecular raw materials of the Orenburg field are 2.6 billion tons of oil.

The study of the results of oil science and practice [1,2,3] and also taking into account the weak permeability of reservoirs of the Orenburg field; the extreme limited volume of the reservoir; mainly sorption capability of rocks, kerogen and bituminous components, enclosed in them; depth of occurrence of the HMWRM, made it possible to choose a tertiary method with carbon dioxide injection as a priority method of mining. It is explained by the ability of $\mathrm{CO}_{2}$ as a volatile solvent to change the filtration-capacitive properties of reservoir (rock permeability) for oil and gas fields with low reservoir temperatures, which is OOGKF.

The gas method is the most efficient and technologically available as the existing technology of separate processing of the Orenburg and Karachaganak gases at the plant produces a significant amount of carbon dioxide ( 70 tons/hour), which must be disposed of according to environmental standards. Currently, $\mathrm{CO}_{2}$ is utilized at Klaus/Sulfren installations, but with the growth of Karachaganak gas supplies, this method becomes impossible due to the increase in the $\mathrm{CO}_{2}$ content in the gas to $6,2 \%$.

To utilize the increasing volume of $\mathrm{CO}_{2}$ it is necessary to build a thermally insulated collector with a length of $1 \mathrm{~km}$ and a diameter of $700 \mathrm{~mm}$ as well as 7 new furnaces with a total cost of 1,37 billion rubles. In addition, this method of disposal requires additional fuel gas in the amount of 30 million $\mathrm{m}^{3} /$ year. Therefore, the most effective alternative method of $\mathrm{CO}_{2}$ recovery can be it's injection into the reservoir (fig.5).

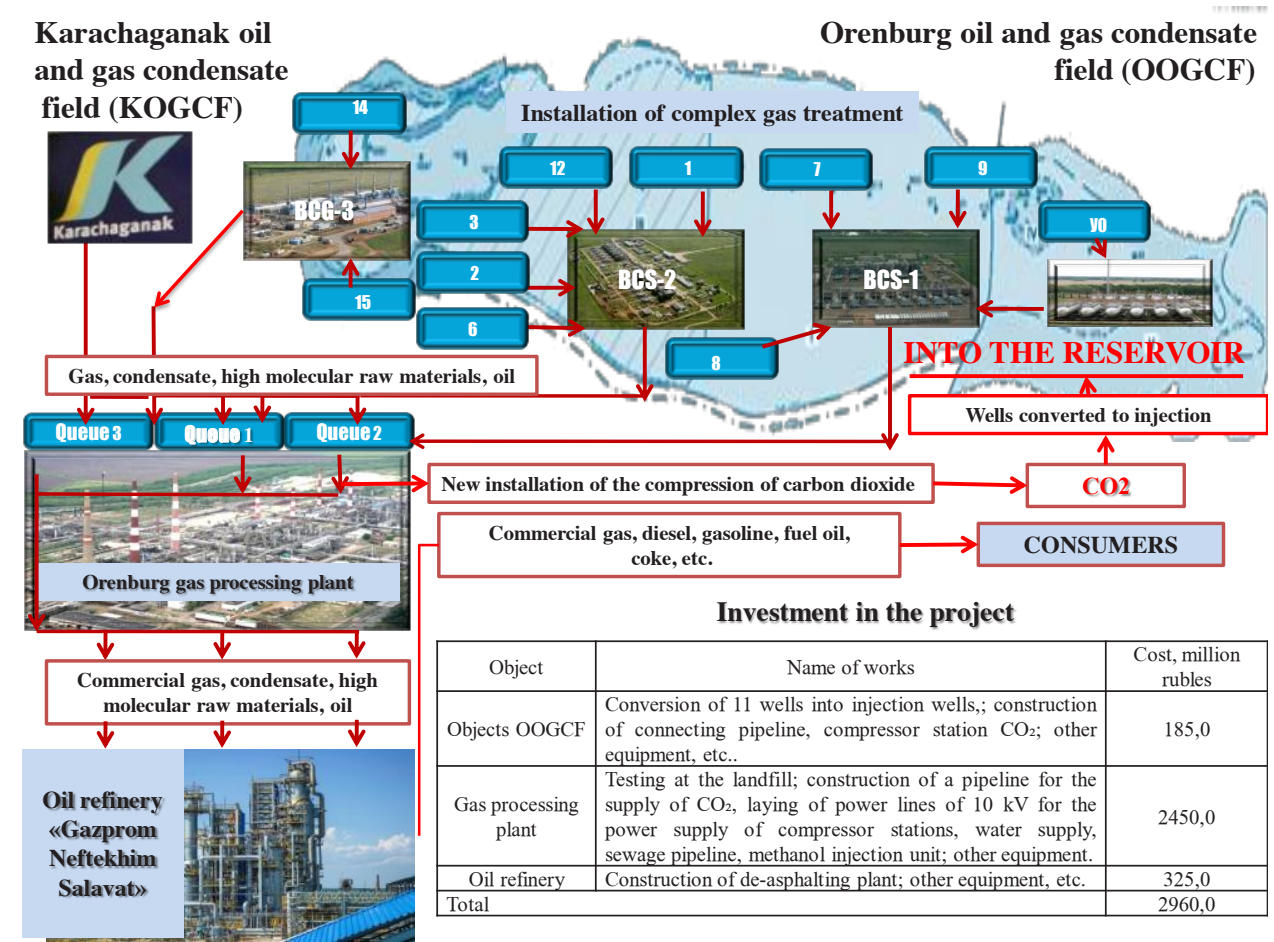

Fig. 5.Scheme of implementation of the gas method of involvement in the development of HMWRM of the field.

In general, the introduction of gas method of mining high-molecular raw materials and it's subsequent processing will allow to:

- reverse the trend of a sharp deterioration in the economic efficiency of the Orenburg oil and gas condensate field, extend the full life cycle of it's development and operation; 
- improve the technology of development of oil rims by using $\mathrm{CO}_{2}$ as a displacing agent;

- slow down the rate of gas wells flooding due to compensation of reservoir pressure drop and prolongation of dry wells waterless operation;

- ensure the growth of gas production associated with high molecular weight raw materials;

- increase the index of extraction of HMWRM during injection of carbon dioxide due to the removal of 60 million tons of retrograde condensate that fell into the near-well areas of the field as a result of reducing reservoir pressure;

- minimize the impact of the Orenburg gas chemical complex on the environment;

- increase the level of capacity utilization of gas processing and oil refineries of Orenburg and Bashkortostan;

- provide growth of revenues in Regional and Federal budgets.

\section{Conclusion}

Thus, the introduction of new technologies will provide in total:

- annual reduction of electricity consumption -2070,468 thousand. $\mathrm{KW}^{*} \mathrm{~h}$;

- saving gas lift gas consumption-100,000 $\mathrm{m}^{3} /$ year;

- reducing the company's expenses for the purchase of fuel and energy resources 6017,196 thousand rubles/year;

- reduction of hydrogen sulfide emissions into the atmosphere - 364 tons/year;

- increase in oil production - 19,557 thousand tons/year;

- increase in the flow rate of oil wells - $10 \%$;

- $80 \%$ reduction of in-shift downtime of borehole equipment associated with hydrate formation;

- reduction of specific energy consumption by $1.73 \%$;

- additional production of commercial sulfur - 341 tons/year;

- reduction of the unit cost of gas production by 2.47 rubles/t, in gas processing $-0,31$ rubles $/ 1000 \mathrm{~m}^{3}$.

In addition, these technologies will allow you to:

- reduce maintenance and repair work;

- ensure the continuity of technological processes of oil and gas production and processing;

- increase the efficiency of equipment use;

- increase the depth of gas processing;

- reduce paraffin and salt sediment, which reduces (and in some cases eliminates) the need for chemical treatment of wells (swabbing);

- reduce the number of power equipment;

- increase the environmental sustainability of the complex;

- reduce the risk of unplanned equipment stops and accidents;

- increase revenues to the budgets of all levels;

- improve the environmental situation in the areas of oil and gas production and processing facilities.

\section{References}

1. N.A. Gafarov, A.I. Glagolev, Gas industry, 11 (682), 48-53 (2012)

2. N.A. Skibitskaya, Gas industry, 11 (698), 24-26 (2013)

3. S.I. Ivanov, Environment protection in oil and gas complex,7, 3-31 (2006) 
4. O.V. Eremenko, Economics and management: problems and solutions, 10 (1) 65-71 (2017)

5. O.V. Eremenko, Problems of economy and management of oil and gas complex, 12, 26$32(2017)$

6. O.V. Eremenko, A.S. Novikova,Improvement of technologies as a basis for effective development of Mature field, Geonature 2019:6-th scientific conference, (Tyumen, 2019)

7. A.S. Novikova, O.V. Eremenko, Intellectualization tools that increase the efficiency of oil and gas condensate field development, Youth Technical Sessions Proceedings, Proceedings of the VI Youth Forum of the World Petroleum Council - Future Leaders Forum, Saint Petersburg, 2019 World Petroleum Council, 190-197 (London, UK, 2019)

8. A.S. Novikova, O.V. Eremenko, Innovations that increase environmental-economic sustainability of the Russian subsoil users, $19^{\text {th }}$ International Multidisciplinary Scentific Geocoference SGEM2019, Ecology, Economics, Education And Legislation Environmental Economics, Tehnology Ltd, 51 «Alexaneder Malinov», 445-451 (Bivd. Sofia, 2019)

9. A.S. Novikova, O.V. Eremenko, Innovations in the extraction of high-molecular raw materials as an effective direction of the oil and gas complex, Geonature 2019:6-th scientific conference, (Tyumen, 2019) 